\title{
Discussion on the Innovation of Mandarin Teaching in Colleges
}

\author{
Changmin Wang \\ Linyi University \\ Linyi, China
}

\begin{abstract}
Compared with other educational stages, in higher education stage, students' pronunciation of words and language habit has formed. They have different language foundations and weak consciousness of language specification. Besides, the mandarin application fails to meet the requirements. The information-based society also influences mandarin teaching in colleges. Compared with the teaching of other courses, the mandarin teaching implements more easily but it is difficult to reach the standard. Therefore, it is imperative to innovate in mandarin teaching through educational idea, teaching form, teaching method, teaching subject and teaching process.
\end{abstract}

\section{Keywords—higher education; mandarin teaching; innovation}

\section{INTRODUCTION}

Since the establishment of People's Republic of China, the popularization of mandarin has made great achievements. The scope and normalization of mandarin application increases considerably. But problems still exist like dialectal mandarin. Colleges are places to train talents and good citizens required by the society. Mandarin is of vital importance for college students. At present, the mandarin teaching in colleges is examination-oriented (Putonghua Proficiency Test), rigid and low efficient, so it is in urgent need of reform and innovation.

\section{CHARACTERISTICS OF MANDARIN TEACHING IN COLLEGES}

Compared with the mandarin teaching in other educational stages, the mandarin teaching in higher education stage has the following characteristics:

First, college students' pronunciation of words and language habit has formed. Most students are between eighteen and twenty-four years old. Students' language habits in words and pronunciation have formed under the dominant or recessive education of family, society and school. At present, most areas in our country belong to dialectal areas or half dialectal areas. Before entering colleges, students mainly depend on dialects to communicate in family and society. In schools, although the basic Chinese education in middle and primary schools of our country clearly requires teachers to teach with standard mandarin (the Putonghua level of Chinese teachers should be second class and first level), in fact, most schools especially rural schools fail to realize mandarin teaching. The requirement exists in name only.
Second, students have great difference in language foundation. College students come from all corners of the country. On one hand, students have different language habits. Influenced by dialects, the "mandarin" of students from different areas is different including language habits and pronunciation. On the other hand, the different reception of language education in basic educational stages, teachers and social environment contribute to the different mandarin basis of students. Some college students have standard pronunciation with clear articulation and a mellow and full tune, but some have difficulty in communication with others. The great differences of educational object make "it is difficult to cater for all tastes" and increase the difficulty in implementing mandarin teaching.

Third, the consciousness of language specification is weak. Except for normal schools, teachers and students in most colleges have weak consciousness of language specification. The specification degree of mandarin is far behind that of English. The mandarin teaching in many colleges is full of randomness and blindness. Some schools fail to provide mandarin course. Some provide only for training of Putonghua Proficiency Test. In mandarin training, teachers' weak consciousness of language specification directly results in the low efficiency of mandarin teaching.

Fourth, students' mandarin application fails to meet the demands. With economic and social development and internationalization, the area coverage of students' employment increases. Students in the same area or school get jobs in different cities. Students employed in the same city come from different areas. Interpersonal communication has increasingly high demands for mandarin. However, the above reasons make students' mandarin application unsatisfactory and fail to meet social demands. It is imperative to strengthen the consciousness of language specification and vigorously promote mandarin education.

Fifth, the information-based society influences the mandarin teaching in colleges. On one hand, online entertainment and leisure activities occupy most of students' spare time so that students spend less time in reading; on the other hand, online videos replace characters. Students spend more time in reading pictures instead of characters. Students' ability in language application declines. The normalization of language application acquired through reading characters also reduces greatly. 


\section{INNOVATE IN MANDARIN TEACHING IN COLLEGES ON THE BASIS OF CHARACTERISTICS}

The innovation of mandarin teaching in colleges should base on its characteristics and problems in the existing mandarin teaching in colleges.

\section{A. Innovation of Educational Idea - Mandarin Teaching Is Unequal to Chinese Education Or Putonghua Proficiency Test and Training}

At present, the weak consciousness of language specification leads to the indifference toward mandarin teaching. Many schools regard mandarin teaching as Chinese education or training before Putonghua Proficiency Test. The three are unequal. Language education is to let students understand language rule, and correctly grasp and apply the rule, speak and write correctly because Chinese is only a "tool". [1] At present, the language education and literary education in our country are implemented through Chinese education. According to the current situation, the Chinese education at higher education stage tends to be humanistic. The Chinese education at the basic educational stage serves as a tool. The earlier the stage, the more obvious the characteristic of tool is. At the higher education stage, students have formed language habits and neglect the language specification. Chinese education becomes the pronoun of literary education. Teachers take "inheritance of culture and promotion of students' spiritual growth" as educational objectives, no longer taking Chinese education as a tool.

Mandarin teaching is equated to the training of Putonghua Proficiency Test. People think it is the success of mandarin teaching to let students pass the Putonghua Proficiency Test through training. Undeniably, Putonghua Proficiency Test is an important index to measure the mandarin application. According to requirements of the country, ministries and commissions, the mandarin level of teachers and students in colleges should reach second level and above, namely the second class and second level, with the description of the mandarin application degree of "several tone pitches are nonstandard and the pronunciation of initial consonant and simple vowel of Chinese syllables is not in place in reading and free talk. Many errors exist in difficult tone. The dialectical tone is unobvious. Dialect words and grammars are used". But we must realize the purpose of mandarin teaching is far from being so. It aims at promoting the normalization of language application.

\section{B. Innovation of Teaching Forms - Combine Dominant Education with Recessive Education}

With the proposition of "explicit knowledge" and "implicit knowledge" in the 1950s, [2] a series of concepts related to implicit knowledge like "recessive education" and "hidden curriculum" attract the attention of researchers from educational and psychological circles. Renowned Canadian linguist Bialystok thinks language knowledge includes explicit and implicit linguistic knowledge, "Explicit linguistic knowledge includes all the knowledge that learners consciously learn. The criteria to judge whether the knowledge is explicit is that whether he can speak the knowledge he has learnt. Implicit linguistic knowledge refers to the knowledge acquired by learners by the light of nature, in order to respond to the knowledge learnt (no matter in understanding or in using). The knowledge that we use automatically without thinking belongs to implicit knowledge, including grammar and vocabulary, etc. Because of the existence of implicit knowledge, learners can feel whether a sentence "sounds" or "feels" correct when there is no direct evidence to prove a sentence is right". [3] Mandarin teaching values the practicality of language, namely the reaction and application of knowledge, the implicit linguistic knowledge. Therefore, it is the best educational form to use recessive education to supplement dominant education in mandarin teaching.

Recessive education means influencing educatee unconsciously through indirect and implicit social activities without plan. In this process, mandarin teaching can happen whenever and wherever possible instead of being restricted to classroom teaching, teachers' instruction and exercises. The recessive education can be unsystematic, such as make students value the application of mandarin and mutual correction in daily communication through influencing their ideas; it can be systematic, such as organize students to read classics of famous people, listen to television news, hold poetry reading meeting, speech contest, debate competition and mandarin grand prix.

\section{Innovation of Teaching Methods - Situational Teaching}

Relevant state departments stipulate the Putonghua level required by various industries and the Putonghua Proficiency Test gradually carries out. Mandarin teaching aims at Putonghua Proficiency Test, similar to the exam-oriented education in CET 4 and CET 6. The direct result of mandarin exam-oriented teaching is that students make fewer mistakes in pronunciation and grammar, but their ability in using language in real life has no improvement. It is because the existing classroom teaching values pronunciation and grammar and neglects language communicative ability. Students must use language to communicate in practice. Compared with the learning of other courses, the practical teaching of mandarin is easier to carry out. The easiest way in classroom teaching is situational teaching, which refers to a teaching method to stimulate students' learning interests and improve learning efficiency through vivid scenes. [4] In situational teaching, teacher can set a specific situation like job interview. Several students act as interviewers and job hunters. Teachers can give guidance on pronunciation, grammar and language application according to the communication in the job interview. Compared with the situation that teachers explain the language application of subjects in job interview cases in class, it is more intuitive and leaves deeper impression on students.

\section{Innovation of Teaching Subject - Humanistic Care in Mandarin Teaching}

Teachers lack emotions and humanistic care in teaching students. Students have more rationality than emotions in language application. It doesn't conform to the ideas of "quality-oriented education" and "people first". In reality, language is not only a communication tool but also the direct reflection of thoughts. It becomes new requirements of mandarin teaching to value students' condition, spiritual desire, 
thoughts and feelings, students' integrated development and improve their spiritual life and moral realm. The humanistic care mentioned in mandarin teaching means the studentoriented idea, respecting their dominant position and meeting their reasonable demands, in order to realize their integrated development, let them speak and use language to express their inward world and care for others. Humanistic care emphasizes the dominant position of people and the shaping of independent personality. It is an important part of humanistic care in mandarin teaching to respect students' dominant position, train their subject consciousness and make them express themselves. Meeting students' reasonable demands means teachers meet students' requirements for mandarin and mandarin teaching. The realization of students' integrated development means carrying out quality-oriented education including knowledge and moral character in mandarin teaching and promoting their development on the basis of knowledge. Humanistic care in mandarin teaching not only includes the teachers' teaching for students in class but also includes the care and love of teachers and students in and after class. Humanistic care makes students apply language, letting them become individuals with thoughts and emotions.

\section{E. Innovation of Teaching Process - Aesthetic Education in Mandarin Teaching}

As previously mentioned, the purpose of mandarin teaching is neither to deal with an exam nor to force students to change the inherent pronunciation and language habits. Its purpose is not confined to language application. More importantly, teachers and students should feel the charm and artistic value of mandarin as a language art. Only by doing this can we love and apply mandarin from the bottom of our heart. Aesthetic education is required in mandarin teaching.

Teachers often value mandarin and neglect students' feelings and cognition of language in mandarin teaching. Therefore, students fail to experience a sense of joy in learning. Aesthetic education in mandarin teaching can adjust students' mental state in mandarin learning and stimulate their enthusiasm and initiative in learning in order to strengthen the effectiveness of mandarin teaching. On the other hand, aesthetic education makes students feel the beauty of mandarin in learning and applying mandarin. Personal intuition towards aesthetic feeling is the most intuitive feelings toward beauty, referring to the beauty brought by initial consonant and simple vowel and intonation of mandarin. The utilitarian of aesthetic feeling is the effect of aesthetic things on people, the reflection of purpose of mandarin teaching as a tool. The learning and appropriate application of mandarin makes students' learning, life and work in the future convenient and makes them establish good image. The emotionality of aesthetic feeling is that aesthetic things promote human emotion. Guiding students to apply mandarin with emotions in mandarin teaching can strengthen the ability in language application and make people perceive the things or emotions expressed by them.

\section{CONCLUSION}

If mandarin is only regarded as a tool for people to communicate, just as most people think, people only need to say mandarin that others can understand. But in reality, with the popularization of mandarin and the standardization of mandarin said by more and more people, it represents the overall image of a people to say standard and fluent mandarin suitable for the situation. It proposes new and higher requirements for mandarin teaching. The innovation of mandarin teaching contributes to the high mandarin level of college students.

\section{REFERENCES}

[1] Cai Ke. "Chinese Education" and "Literary Education"-Interview of Mr. Feng Zhongyun [N], China Reading Weekly, Nov.20, 2002

[2] Poanyi, M. The Study of Man. Chicago [J].University of Chicago Press, 1959.

[3] Bialystok,E.1978. Quoted from: Zheng Yurong. Relationship between Implicit Knowledge and Explicit Knowledge and Its Influence on Language Teaching [D], Harbin: Heilongjiang University, 2002

[4] Gu Mingyuan. Education Dictionary [M], Shanghai: Shanghai Educational Publishing House, 1998: 1129 